\title{
Mechanisms of Lung Fibrosis Resolution
}

\author{
Stephan W. Glasser, * James S. Hagood, ${ }^{\dagger \ddagger}$ Simon Wong, ${ }^{\dagger}$ Carmen A. Taype, ${ }^{\S}$ Satish K. Madala, ${ }^{\Uparrow}$ and \\ William D. Hardie
}

\begin{abstract}
From the Divisions of Pulmonary Biology* and Pulmonary Medicine," Cincinnati Children's Hospital Medical Center, Cincinnati, Ohio; the Divisions of Pediatric Respiratory Medicine $e^{\dagger}$ and Pulmonary, Critical Care, and Sleep Medicine, ${ }^{\S}$ University of California-San Diego, La Jolla, California; and the Division of Respiratory Medicine, ${ }^{\ddagger}$ Rady Children’s Hospital of San Diego, San Diego, California
\end{abstract}

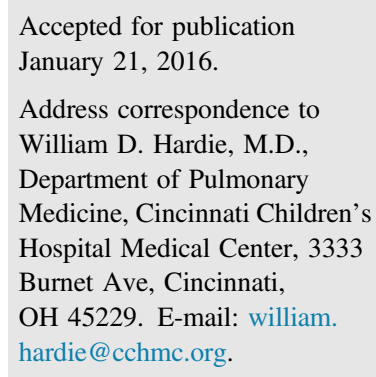

\begin{abstract}
Fibrogenesis involves a dynamic interplay between factors that promote the biosynthesis and deposition of extracellular matrix along with pathways that degrade the extracellular matrix and eliminate the primary effector cells. Opposing the often held perception that fibrotic tissue is permanent, animal studies and clinical data now demonstrate the highly plastic nature of organ fibrosis that can, under certain circumstances, regress. This review describes the current understanding of the mechanisms whereby the lung is known to resolve fibrosis focusing on degradation of the extracellular matrix, removal of myofibroblasts, and the role of inflammatory cells. Although there are significant gaps in understanding lung fibrosis resolution, accelerated improvements in biotechnology and bioinformatics are expected to improve the understanding of these mechanisms and have high potential to lead to novel and effective restorative therapies in the treatment not only of pulmonary fibrosis, but also of a wide-ranging spectrum of chronic disorders. (Am J Pathol 2016, 186: 1066-1077; http://dx.doi.org/ 10.1016/j.ajpath.2016.01.018)
\end{abstract}

Fibrogenesis in the lung involves a balance between factors that promote the biosynthesis and accumulation of extracellular matrix (ECM) components and the pathways that deactivate or eliminate the effector cells and remove the excess ECM. Ongoing basic and translational studies continue to improve our understanding of the cells, mediators, and pathways leading to the initiation and progression of fibrosis. Progress in these research efforts was highlighted by the 2014 Federal Drug Administration approval of pirfenidone and nintedanib for idiopathic pulmonary fibrosis (IPF), both of which significantly slow disease progression. ${ }^{1,2}$ However, novel therapies to promote the resolution of fibrosis have yet to be identified. Because most patients have a significant fibrotic burden at the time of clinical presentation, understanding the basic mechanisms mediating the lungs' capacity to resolve fibrosis is critically important, and may lead to novel therapeutic strategies to actually reverse established disease. Successful fibrosis resolution comprises identification and elimination of the fibroproliferative stimulus, clearance of transformed myofibroblasts, degradation and clearance of ECM, and reconstitution of damaged lung epithelium and alveoli. This review will summarize current studies focused on the primary mechanisms of lung fibrosis resolution and the modifying roles of inflammatory cells that either facilitate or interfere with these processes.

\section{Reversibility of Tissue Fibrosis}

Fibrosis has traditionally been thought to be an irreversible process, the end stage of disordered wound healing, and thus refractory to therapeutic intervention beyond prevention of progressive scarring. However, a growing body of data now reveals the highly plastic nature of

\footnotetext{
Supported in part by NIH/National Heart, Lung and Blood Institute (NHLBI) grants HL082818 (J.S.H. and S.W.), HL111169 (J.S.H. and C.A.T.), R01HL111169-02S1 (J.S.H. and C.A.T.) and U10-HL-101800 (W.D.H.); NIH National Institute of Arthritis and Musculoskeletal and Skin Diseases (NIAMS) grant 1R03AR062832-01A1 (S.K.M.); NIH National Institute on Aging (NIA) grant 1R21AG047473-01A1 (W.D.H.); a Parker B. Francis Fellowship (W.D.H.); and American Heart Association grant 12SDG9130040 (S.K.M.).
}

Disclosures: None declared. 

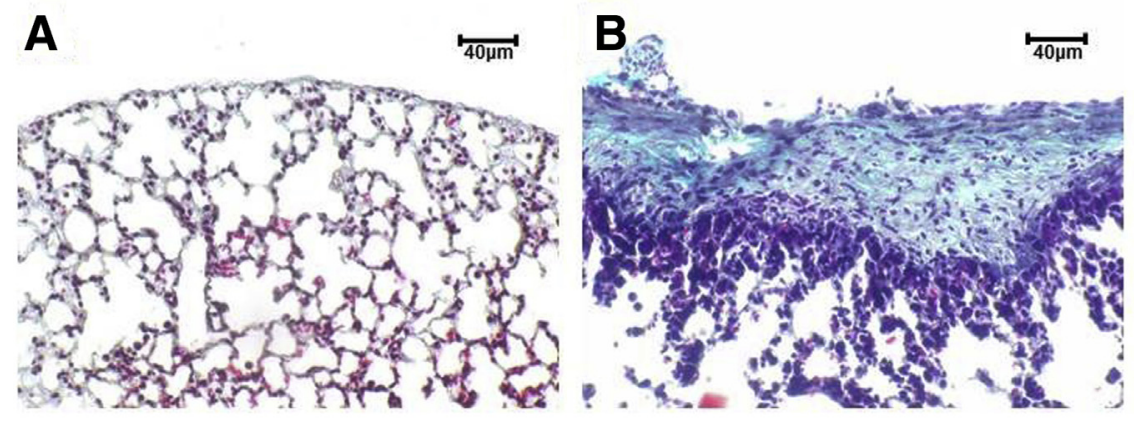

Figure 1 Conditional TGF $\alpha$ transgenic mice induce transgene expression following enteral administration of doxycycline (Dox). Pentachrome stains of subpleural regions in TGF $\alpha$ mice without Dox (A) after 42 days of Dox (B) and 42 days on Dox followed by 126 days off Dox (C). Right ven-
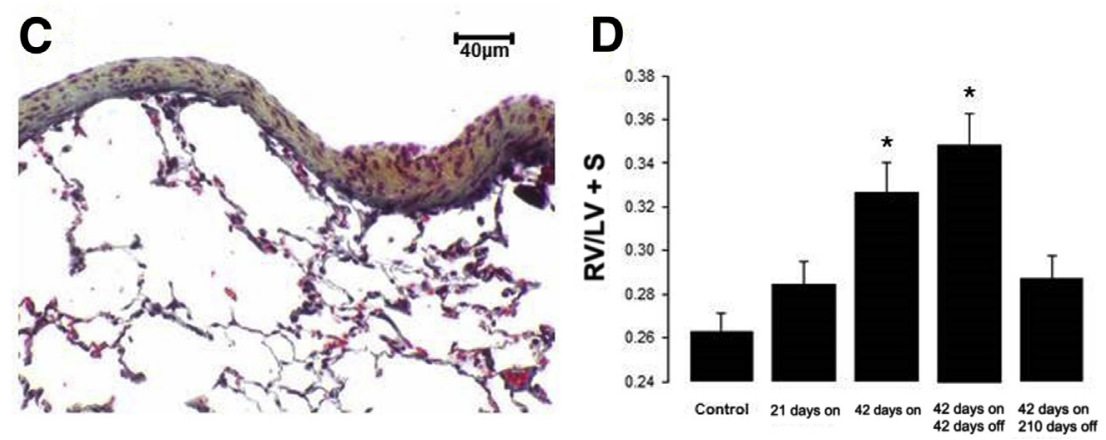
tricular (RV) hypertrophy measured by comparing RV divided by left ventricle plus septal weight (RV/ $\mathrm{LV}+\mathrm{S}$ ) at intervals on and off Dox (D). Reprinted from Hardie et $\mathrm{al}^{12}$ with permission of the American Thoracic Society. ${ }^{\star} P<0.05$ versus control.

organ fibrosis that can regress in certain circumstances. In the kidney, established glomerulosclerosis is reversible, and the interstitial matrix can resolve. ${ }^{4}$ Studies in rodents demonstrate reversal of liver fibrosis in the experimental models of carbon tetrachloride or alcohol intoxication and bile duct ligation. ${ }^{5}$ Although fibrosis regresses in these models, it is not fully reversible in advanced disease. Prolonged damage in liver fibrosis models leads to increased acellular ECM deposition and a steep decline of potential reversibility. Factors associated with inefficient fibrolysis in the liver include advanced vascular remodeling with architectural distortion, extensive cross-linking of ECM components hindering proteolytic removal, and the disappearance of cells that digest and degrade scar tissue. ${ }^{6}$

Chronic infection with hepatitis $\mathrm{C}$ virus is a common cause of liver fibrosis, and the most compelling evidence that spontaneous resolution of fibrosis is possible in humans comes from studies examining the response to antiviral treatments. There is clear histological evidence from biopsy tissue of patients with mild-to-moderate fibrosis who are successfully treated for hepatitis $\mathrm{C}$ virus infection indicating resolution of the fibrosis seen in the index biopsy. ${ }^{7}$ Although fibrosis in the liver regresses, it is not fully reversible in patients with cirrhosis. However, even in extensive cirrhosis, the need for liver transplant is often not directly because of the fibrosis, but rather the sequelae of fibrosis causing portal hypertension, variceal bleeding, and ascites.

Multiple animal models of lung fibrosis have been developed, primarily using acute injury or transgenic approaches. ${ }^{8}$ Although no animal model yet fully recapitulates the histological pattern seen in IPF or other interstitial lung diseases, these models have generated important insights into the pathobiology of fibroproliferation. Fibrosis in most of these models is reversible, with complete or near complete restitution of lung architecture after the inciting fibrogenic agent is removed, such as after a single intratracheal administration of bleomycin. More durable pulmonary fibrosis is produced with intratracheal administration of high-dose amphibole asbestos fibers, intratracheal fluorescein isothiocyanate in susceptible mouse strains, and repetitive doses of systemic bleomycin. $^{9-11}$ Similar to liver fibrosis, the degree of reversibility in the lung appears to be related to the duration or intensity of the fibrogenic trigger. Transgenic mice conditionally overexpressing transforming growth factor (TGF)- $\alpha$ in the lung epithelium develop a profound fibrotic burden leading to cachexia, secondary pulmonary hypertension, marked alterations in lung mechanics, and death. When the TGF- $\alpha$ expression is extinguished after 4 weeks of expression, there is complete resolution of histological fibrosis. However, mice exposed to longer periods of TGF- $\alpha$ expression show persistent subpleural fibrosis up to 126 days after discontinuation of TGF- $\alpha$ expression (Figure 1, A-C). ${ }^{12}$ Despite this residual fibrosis, mice have complete or near complete recovery of physiological changes, including secondary pulmonary hypertension (Figure 1D). Similarly, a recently published model of sepsis-induced acute lung injury in baboons revealed biochemical and radiographic evidence of persistent pulmonary fibrosis in long-term survivors studied between 6 and 27 months after the acute episodes. ${ }^{13}$ However, only one of the six long-term survivors demonstrated static lung compliance values lower than 
healthy control baboons. Together, these animal studies support the concepts that the functional impairments from even severe lung fibrosis can be recoverable and that residual fibrosis may have minimal physiological impact.

The reversibility of lung fibrosis in human disease is less clear and likely depends on the specific insult, age, sex, and other modifying conditions of the patient. Acute respiratory distress syndrome is characterized histologically, in its organizing phase, by fibroblast accumulation and deposition of ECM in the lung. ${ }^{14}$ Studies assessing long-term outcomes in acute respiratory distress syndrome survivors report persistent lung dysfunction and computed tomographic abnormalities in only subsets of subjects, suggesting significant fibrosis resolution for most patients. ${ }^{15,16}$

In summary, animal models of fibrosis in the kidney, liver, and lung indicate the potential to reverse a substantial fibrotic burden and return to near predisease function after the fibrogenic insult is extinguished. The concept of fibrosis reversal in solid organs is supported in human disease, where liver cirrhosis caused by hepatitis infection demonstrates marked resolution after antiviral treatment. However, the lung lacks the regeneration capacity of the liver, and the potential to significantly reverse more extensive lung fibrosis, such as develops in advanced cystic fibrosis or IPF, is unknown. ${ }^{17}$ The emergence of new pharmacological treatments for these conditions targeting the underlying disease process, such as modulators and potentiators for cystic fibrosis, may provide insight into the extent of the lung's capacity to resolve extensive pulmonary fibrosis.

\section{Degradation of the Extracellular Matrix}

\section{Composition of the Extracellular Matrix in Fibrosis}

The ECM is a heterogeneous, highly dynamic, threedimensional tissue providing structural support as well as spatial and temporal contextual cues to cells during embryonic development, wound repair, and tissue homeostasis. ${ }^{18}$ In the human lung, the ECM is composed primarily of type I and III collagen in approximately a 2:1 ratio, which provides tensile strength; elastin, which provides the structural framework and elasticity of the alveolar wall; and laminin and collagen IV, which constitute the bulk of the alveolar and airway basement membranes. ${ }^{18-20}$ This relationship changes in lung fibrosis. Studies examining ECM composition from patients with a variety of fibrotic diseases demonstrate an increase in total type I and III collagen in early lung fibrosis, with type III collagen predominant in the thickened alveolar septa and interstitium. ${ }^{21}$ In more established areas of scar formation, there was almost exclusive type I collagen, representing approximately $80 \%$ of the total collagen in IPF. ${ }^{21,22}$ Increases in other constituents of the ECM include types V, VI, and VII collagens, fibronectin, elastin, hyaluronan, and glycosaminoglycans. ${ }^{18,23,24}$

\section{Extracellular Pathways of ECM Degradation}

Matrix degradation likely occurs through a multistep process that involves extracellular protease-mediated cleavage, recognition of fibrils by membrane-bound receptors, and cellular uptake with intracellular lysosomal degradation of cleaved matrix fragments. ${ }^{24,25}$ Several enzymatic families are known to degrade matrix in the lung through the extracellular pathway, including matrix metalloproteinases (MMPs), cysteine proteinases (cathepsins B and L), and serine proteinases (plasmin and plasminogen activator). The foremost proteolytic enzymes involved in extracellular cleavage are the MMPs. The MMPs are a family of zinc- and calcium-dependent endopeptidases produced by both connective tissue and inflammatory cells. Through recognition of specific cleavage sites, the MMPs degrade ECM, including fibrillar and nonfibrillar collagens and elastin. ${ }^{24,26}$ Primarily on the basis of in vitro degradation assays, the MMPs can be grouped according to the enzymatic substrate to include collagenases, gelatinases, metalloelastases, and stromelysins. The collagenases, which include MMP-1, MMP-8, and MMP-13, are believed to be central toward degrading fibrotic tissue owing to the high predominance of type I collagen in established areas of scar formation. Fragments of the cleaved collagen are hydrolyzed to gelatin, which is further degraded by the gelatinases, specifically MMP-2 and MMP-9. Metalloelastase (MMP-12) has potent elastin-degrading activity, and stromelysin (MMP-3) has a wide substrate profile with activity against collagens, laminin, and fibronectin.

Tissue inhibitors of metalloproteases (TIMPs) are a family of four homologous members of soluble proteins that bind to active MMPs. The prevailing hypothesis for ECM turnover has been a balance in activity between extracellular MMP and the TIMP family. However, gene mutation studies do not support this paradigm and demonstrate contradictory roles for MMPs and TIMPS in lung fibrosis. For instance, studies in MMP-9 and MMP-12 knockout mice, administered bleomycin or other fibrogenic challenges, reveal either a profibrotic effect, an antifibrotic effect, or no effect on the development of lung fibrosis. ${ }^{23}$ Loss of TIMPs would be expected to lead to enhanced matrix proteolysis; however, TIMP3 knockout mice demonstrated enhanced fibrosis after bleomycin associated with persistent neutrophil influx. ${ }^{27}$ Mice lacking TIMP1 have similar severity of fibrosis but greater neutrophilic inflammation compared with wild-type mice after bleomycin injury. ${ }^{28}$ These studies and others now demonstrate that the MMPs and TIMPs influence several cellular processes, including proliferation, survival, and inflammation, that directly or indirectly influence myofibroblast activation and ECM turnover. ${ }^{23,24,29,30}$

Cross-linking of collagen and elastin are posttranslational modifications of the ECM that can hinder fibrosis resolution by preventing extracellular proteolytic enzymes from accessing binding sites. One family of 


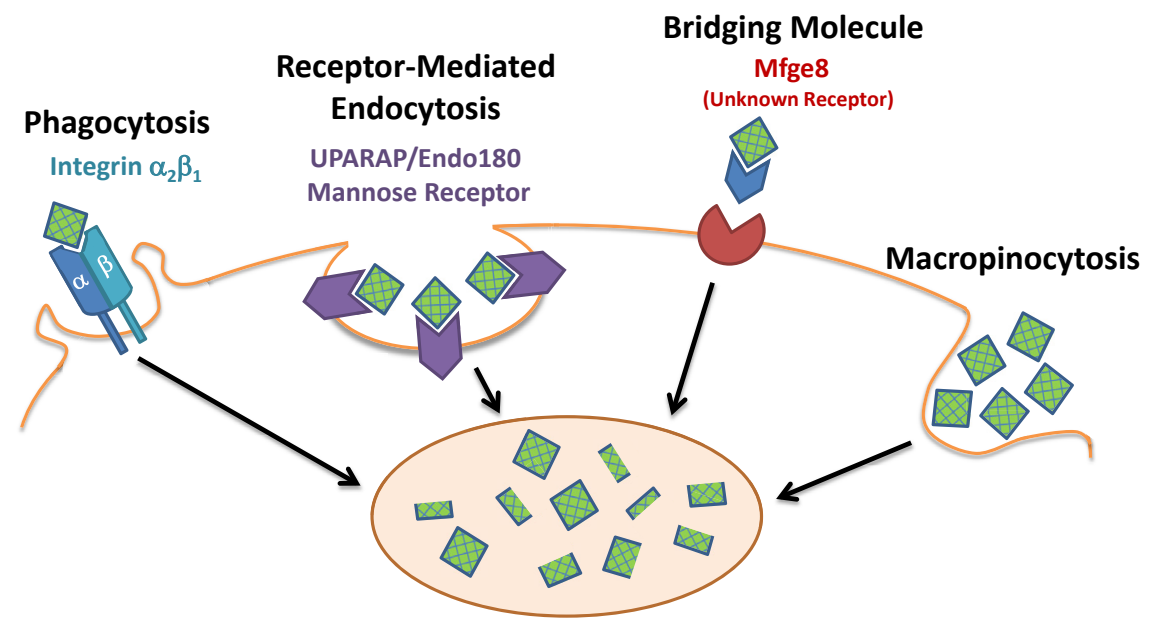

Figure 2 Collagen internalization is mediated by macropinocytic, phagocytic, and endocytic pathways where fragments are ultimately degraded by the lysosome. Figure modified from McKleroy et $\mathrm{al}^{24}$ with permission from the American Physiological Society. Mfge8, milk fat globule-epidermal growth factor 8; UPARAP, urokinase plasminogen activator receptor-associated protein.

\section{Lysosomal Degradation}

enzymes mediating this cross-linking is lysyl oxidase and its homologues (lysyl oxidase-like enzymes 1 to 4 ). ${ }^{31}$ The lysyl oxidases catalyze the oxidation of primary amines, such as lysine residues into aldehydes. These aldehydes then react with other aldehydes or amines to cross-link collagen or elastin. Recent studies demonstrate that inhibition of lysyl oxidase-like-2 experimentally reduced myocardial fibrosis and also prevented and reversed bleomycin-induced lung fibrosis. ${ }^{32,33}$ Thus, although manipulating extracellular proteases may be premature because of the limited understanding of their precise function in ECM turnover, targeting pathways that allow better access of extracellular proteases to the ECM is promising. Monoclonal antibodies to lysyl oxidaselike-2 have been tested in phase 2 trials in IPF, and smallmolecule lysyl oxidase-like-2 selective inhibitors have been developed and are expected to enter phase 1 trials for the treatment of pulmonary fibrotic disease.

\section{Intracellular Pathways of ECM Degradation}

The intracellular pathways of ECM degradation are comparatively less well studied than the extracellular degradation processes. Collagens that have been precleaved by collagenases are internalized more efficiently than intact collagen, thereby allowing cells to clear and recycle matrix components. ${ }^{34}$ The primary processes mediating intracellular collagen degradation include recognition and internalization of collagen fragments, where they are ultimately degraded into the lysosomal network by cysteine proteinases. Several pathways have been shown to internalize collagen fragments (Figure 2). The $\alpha_{2} \beta_{1}$ and $\alpha_{3} \beta_{1}$ bind collagen internalizing them for lysosomal degradation, and inhibition of these integrins reduces phagocytosis of collagen-coated beads. ${ }^{35} \mathrm{~A}$ receptor-mediated endocytosis pathway of collagen uptake has been described for the transmembrane urokinase plasminogen activator receptor-associated protein. This receptor, which is expressed predominantly in fibroblasts, can bind and internalize both fibrillar and nonfibrillar collagens to the lysosome for degradation before recycling to the plasma membrane. ${ }^{36}$ Collagen IV and gelatin internalization were nearly ablated in urokinase plasminogen activator receptor-associated protein deficient mouse lung fibroblasts in an integrin-independent mechanism. ${ }^{34}$ Compared with controls, mice deficient in urokinase plasminogen activator receptor-associated protein exhibit increased total lung hydroxyproline content 28 days after bleomycin injury than controls without alterations in inflammation, or rates of collagen synthesis.

The extracellular glycoprotein milk fat globule-epidermal growth factor 8 (Mfge8) is a soluble glycoprotein that mediates collagen uptake by binding collagen fragments for uptake by macrophages. Mice deficient in Mfge8 demonstrate greater total lung hydroxyproline content 28 days after bleomycin injury than controls. This increased fibrosis was not associated with increased inflammation, impaired apoptotic cell clearance, or changes in rates of collagen synthesis, but rather a defect in collagen turnover. Mfge8 knockout macrophages exhibited defective collagen uptake that could be rescued by recombinant Mfge 8. ${ }^{37}$ Mfge8 also negatively regulates inflammation and autoimmunity by facilitating the clearance of apoptotic cells. ${ }^{38}$ This dual role suggests that the failure to resolve may be imprecise coordination of effectors, such as Mfge8, that bridge apoptosis and enzymatic ECM breakdown.

In summary, proteolytic degradation of the ECM is of vital importance in fibrosis resolution, but still relatively understudied. The specific extracellular proteinases essential to degrade lung ECM in vivo remain under investigation; and while interfering with intracellular pathways of ECM degradation, they lead to greater fibrosis experimentally. However, it remains unclear if defects in these pathways lead to progressive disease. Advances in gene deletion studies may allow future 
Table 1 Factors and Mechanisms Affecting Lung Myofibroblast Dedifferentiation, Apoptosis, and Aging

\begin{tabular}{|c|c|c|c|}
\hline Factors & Potential mechanisms & Experimental models & Reference \\
\hline c-FLIP & Inhibits apoptosis via direct apoptosis inhibitor & Mouse and IPF myofibroblasts & Golan-Gersti et $\mathrm{al}^{48}$ \\
\hline FGF-1 & Inhibit differentiation via blocking Smad2 & Primary human fibroblasts & Ramos et $\mathrm{al}^{49}$ \\
\hline MyoD & Induces differentiation via TGF- $\beta 1$ & Normal human fibroblast & Hecker et $\mathrm{al}^{40}$ \\
\hline NFAs & Inhibit differentiation via PPAR- $\gamma$ up-regulation & IPF/normal human fibroblasts, murine in vivo & Reddy et $\mathrm{al}^{50}$ \\
\hline Nox4-Nrf2 & $\begin{array}{l}\text { Inhibits apoptosis in aged cells via oxidant } \\
\text { imbalance }\end{array}$ & Mouse and IPF myofibroblasts, murine in vivo & Hecker et $\mathrm{al}^{51}$ \\
\hline PGE2 & Inhibit differentiation via FAK activation & Normal human fibroblasts & Garrison et $\mathrm{al}^{54}$ \\
\hline Rho/ROCK & Induces differentiation and survival via MKL1 & IPF/normal human fibroblasts, murine in vivo & Zhou et $\mathrm{al}^{41}$ \\
\hline SRF/MRTF & $\begin{array}{l}\text { Induces differentiation and survival via XIAP } \\
\text { and PAI-1 }\end{array}$ & Normal fibroblasts, murine in vivo & Sisson et $\mathrm{al}^{55}$ \\
\hline Survivin & Inhibits apoptosis via direct apoptosis inhibitor & Normal human fibroblast & Horowitz et $\mathrm{al}^{56}$ \\
\hline
\end{tabular}

c-FLIP, c-Fas-like IL 1 $\beta$-converting enzyme-inhibitory protein; FGF, fibroblast growth factor; IPF, idiopathic pulmonary fibrosis; MRTF, myocardin-related transcription factor; MyoD, myoblast determination protein 1; NFA, nitrated fatty acid; Nrf2, nuclear factor erythroid 2-related factor 2; PAI, plasminogen activator inhibitor; PGE, prostaglandin E; PI3K, phosphatidylinositol 3-kinase; PPAR, peroxisome proliferator-activated receptor; ROCK, Rho-associated kinases; SRF, serum response factor; TGF, transforming growth factor; XIAP, X-linked inhibitor of apoptosis.

studies to experimentally track production and alterations of each of the functionally relevant protease members and pathways in vivo during fibrosis resolution to determine their impact in spontaneous resolution. ${ }^{23}$

\section{Removal of Myofibroblasts in Lung Fibrosis}

\section{Impact of Myofibroblasts}

Myofibroblasts are differentiated cells with features of both fibroblasts and smooth muscle cells, and are characterized by a spindle or stellate morphology with intracytoplasmic stress fibers, a contractile phenotype, and expression of $\boldsymbol{\alpha}$-smooth muscle actin ( $\boldsymbol{\alpha}$-SMA). ${ }^{39,40}$ Myofibroblasts are essential in normal wound healing by facilitating wound closure and synthesis of ECM proteins. ${ }^{3}$ Termination of the reparative response that leads to normal wound healing includes the elimination of myofibroblasts from granulation tissue. In contrast, the persistence of myofibroblasts in injured tissues is associated with nonresolving and progressive fibrosis in the lung and other organs. ${ }^{39,41}$ Because myofibroblasts are the main effectors of fibrosis, successful resolution is dependent on inhibiting myofibroblast differentiation from precursor cells and eliminating active myofibroblasts. Myofibroblast differentiation is triggered by several mediators, including cytokines, growth factors, and ECM composition, as recently reviewed. ${ }^{39}$ However, even if differentiation can be inhibited, persistent myofibroblasts can induce a feedforward mechanism for maintaining the myofibroblast phenotype and inducing neighboring cells into fibrotic and dysfunctional cells through mechanotransductionmediated up-regulation of profibrotic and prosurvival genes. ${ }^{39,41,42}$ Therefore, elimination of embedded myofibroblasts is paramount to promoting resolution. There are three primary molecular mechanisms mediating myofibroblast removal: dedifferentiation, apoptosis, and senescence. A greater understanding of these mechanisms and determining how they may be manipulated has significant potential to lead to the development of novel antifibrotic therapies.

\section{Role of Dedifferentiation in Removing Myofibroblasts}

Cell dedifferentiation is the regression of a cell from a more specialized state back to an earlier developmental stage, a process that in the extreme case confers pluripotency. The mechanisms underlying cell-specific dedifferentiation have been indicated to be critical in developmental biology, ${ }^{43}$ regenerative medicine, ${ }^{44}$ and tumorigenesis. ${ }^{45}$ Myofibroblast differentiation was previously considered irreversible. However, studies using Cre-lox $P$-based genetic labeling of myofibroblasts demonstrated that the myofibroblast phenotype is reversible in spontaneous recovery after experimental models of carbon tetrachloride - or alcohol-induced liver fibrosis. ${ }^{46,47}$ Factors and mechanisms have recently been identified that induce dedifferentiation of lung myofibroblasts in vitro (Table 1). ${ }^{40,41,48-59} \mathrm{MyoD}$ is a master transcriptional regulator of myogenic differentiation and mediates TGF- $\beta 1$-induced myofibroblast differentiation of human lung fibroblasts. ${ }^{40,60}$ Down-regulation of endogenous MyoD with RNA interference in myofibroblasts was associated with dedifferentiation and increased proliferation. ${ }^{40}$

TGF- $\beta 1-$ stimulated normal human lung fibroblasts incubated with fibroblast growth factor-1 demonstrate reduced collagen gel contraction and a significant decrease 
in the percentage of $\alpha$-SMA-expressing myofibroblasts. ${ }^{49}$ Dedifferentiation of myofibroblasts after fibroblast growth factor-1 administration was associated with reduced Smad2 phosphorylation. These findings support a direct dedifferentiation effect of fibroblast growth factor-1 by antagonizing TGF- $\beta$ actions, an observation also observed in corneal myofibroblasts. ${ }^{61}$

Thy-1 is a cell surface glycoprotein present on normal lung fibroblasts but is epigenetically silenced in myofibroblasts within the fibroblastic foci of IPF via DNA hypermethylation and chromatin modifications. ${ }^{62}$ DNA methyltransferase inhibition and histone deacetylase inhibition restored Thy-1 expression in primary rat lung myofibroblasts and reduced $\alpha$-SMA expression. ${ }^{58}$

Prostaglandin E2 (PGE2) is an endogenously produced lipid mediator that inhibits multiple fibroblast functions, including proliferation, collagen production, and differentiation. ${ }^{39}$ In fetal and adult lung fibroblasts, the addition of PGE2 reversed TGF- $\beta 1$ and endothelin-1-induced myofibroblast differentiation via inhibition of focal adhesion kinase activation. ${ }^{54}$ This effect was not explained by apoptosis, and reintroduction of TGF- $\beta 12$ days after the addition of PGE2 prompted dedifferentiated fibroblasts to reexpress $\alpha$-SMA, indicating redifferentiation to myofibroblasts. Furthermore, PGE2 was capable of directionally reversing more than half of the myofibroblast genes whose expression was altered by TGF- $\beta 1$, thereby demonstrating the plasticity of the myofibroblast phenotype at a transcriptomic level. ${ }^{63}$ However, PGE2, when administered to mice 14 days after bleomycin, failed to provide significant therapeutic effects on lung function or fibrosis. ${ }^{64}$

Nuclear factor erythroid 2-related factor 2 (NRF2) is regarded as a master regulator of cellular resistance to oxidants and regulates expression of genes, limiting the inflammatory and fibrotic responses. ${ }^{39}$ In primary IPF and normal lung fibroblasts, siRNA activation of NRF2 by either Keap1 siRNA or sulforaphane induced myofibroblast dedifferentiation with down-regulation of $\alpha$-SMA, along with reduced cell proliferation, migration, and contraction, and was associated with restored oxidant/antioxidant balance in the cells. ${ }^{52}$ NRF2 knockdown abolished Suforaphane's dedifferentiation effects, suggesting that they were NRF2 mediated. However, these in vitro observations did not translate in vivo because sulforaphane administration was unsuccessful in altering bleomycininduced pulmonary fibrosis in mice. ${ }^{52}$

Endogenous nitrated fatty acids are potent agonists of peroxisome proliferator-activated receptor $\gamma$, which have been shown to exhibit antifibrotic activity in the lung through SMAD inhibition. ${ }^{65,66}$ Cultured IPF myofibroblasts treated with the most common nitrated fatty acids in human plasma, 10-nitro-oleic acid, increased peroxisome proliferator-activated receptor $\gamma$ expression, while reversing myofibroblast differentiation, as assessed by $\alpha$-SMA levels and contractility. ${ }^{50}$ More important, intratrachael treatment of mice with 10-nitro-oleic acid for 7 successive days beginning 21 days after bleomycin injection reduced the total lung collagen content and $\alpha$-SMA protein levels. These findings are unique by supporting that nitrated fatty acids can reverse collagen deposition and myofibroblast differentiation both in vitro and in vivo. ${ }^{50}$

Taken together, several candidate pathways have now been identified that induce dedifferentiation of lung myofibroblasts in vitro. Future preclinical studies will determine whether these pathways have the potential to be manipulated to induce myofibroblast dedifferentiation as a novel therapy for late-stage fibrotic disorders.

\section{Role of Apoptosis in Removing Myofibroblasts}

There are three pathways of cell death: apoptosis, autophagy, and necrosis. The particular mode of cell death may predominate depending on the cell type and the injury. ${ }^{67}$ There is significant overlap and cross talk between different modes of cell death, and distinctions are not always clear; however, almost all of the accumulated data in lung fibrosis relate to apoptotic cell death. ${ }^{67,68}$

Apoptosis is mediated by the concerted action of a set of cysteine proteases known as caspases. There are two major pathways of apoptosis, the death receptor and mitochondrial pathways, which converge to activate effector caspases, caspase- 3 and caspase-7, which execute the apoptotic cell death program. ${ }^{67,68}$ Apoptosis has been shown to be the primary mechanism of myofibroblast elimination in granulation tissue during the resolution phase of normal wound repair. ${ }^{69}$ Apoptosis has also been identified as a primary mechanism of myofibroblast removal in the bleomycin lung fibrosis model. ${ }^{55,70,71} \mathrm{An}$ accumulating body of literature demonstrates that lung fibroblasts and myofibroblasts in both mouse fibrosis models and IPF acquire an apoptosis-resistant phenotype. ${ }^{41,48,55,59,70,71}$ Several mechanisms by which myofibroblasts evade apoptosis have been identified, ${ }^{72}$ and several common mechanistic themes have emerged. First, soluble profibrotic mediators that activate myofibroblasts, such as TGF- $\beta 1$, also promote resistance to apoptosis. ${ }^{57}$ Second, prosurvival protein kinases, including phosphatidylinositol-3 kinases, which are activated by soluble fibrogenic mediators in normal lung fibroblasts, are expressed at higher levels in IPF fibroblastic foci. ${ }^{73,74}$ Third, endogenous inhibitors of apoptosis, such as Fas-like IL $1 \beta$-converting enzyme-inhibitory protein and $\mathrm{X}$-linked inhibitor of apoptosis, are induced by soluble profibrotic mediators and expressed at increased levels in fibrotic lung fibroblasts. ${ }^{4,56,59}$ Fourth, the composition and biomechanical properties of the ECM can modulate fibroblast resistance to apoptosis. ${ }^{41,75}$ Fifth, epigenetic alterations, such as methylation of the Thy-1 promoter in fibroblastic foci of IPF, have been linked to resistance to apoptosis. $^{62,76}$

Several recent murine studies demonstrate that pharmacological strategies to induce myofibroblast apoptosis after fibrosis were already established and can accelerate resolution. ${ }^{41,55,70,71}$ The histone deacetylase inhibitor 
suberoylanilide hydroxamic acid induced apoptosis in the myofibroblasts of IPF patients through up-regulation of the proapoptotic gene $B a k$ and down-regulation of the antiapoptotic gene $B c l-x L$ by specific histone modifications and DNA methylation changes. ${ }^{71}$ Furthermore, suberoylanilide hydroxamic acid reduced postinflammatory fibrosis in bleomycin-treated mice mediated, at least in part, by modulating Bak and $B c l-x l$ levels in the lungs. ${ }^{71}$ Targeting myofibroblast stress fiber formation through, either the Rho-associated kinase pathway or myocardin-related transcription factor/serum response factor signaling, induced preexisting lung myofibroblasts of IPF patients to undergo apoptosis. ${ }^{41,55}$ Specific pharmacological agents targeting these pathways also reduced postinflammatory lung fibrosis in bleomycin-treated mice. ${ }^{41,55}$ Pharmacological targeting inhibitor of apoptosis family proteins X-linked inhibitor of apoptosis and cellular IAP reduced postinflammatory lung fibrosis in bleomycin-treated mice while promoting fibroblast/ myofibroblast apoptosis. ${ }^{70}$

In summary, experimental evidence demonstrates that strategies that augment apoptosis in myofibroblasts hasten lung fibrosis resolution. These findings thereby support apoptosis of myofibroblasts as an important mechanism in normal lung fibrosis resolution. Combined with the growing evidence supporting myofibroblast resistance to apoptosis in IPF, these emerging approaches also have strong potential to lead to novel therapies to treat fibrotic lung disease.

\section{Role of Senescence and Aging in Removing Myofibroblasts}

Cellular senescence is an adaptive, stable form of cell cycle arrest associated with loss of proliferative activity, persistence of active metabolism, and resistance to apoptosis. Senescent cells are refractory to mitogenic stimulation by activating regulators of cell cycle progression, including p53, p21, and p16. ${ }^{77,78}$ Extrinsic senescence develops after cellular damage or stress and is hypothesized to be an important mechanism to constrain the malignant progression of tumor cells. ${ }^{79}$ Replicative senescence is an intrinsic mechanism whereby there is a limitation in the number of times that cells can divide and is believed to contribute to aging-related pathologies by the acquisition of the senescence-associated secretory phenotype, which enables cells to secrete a variety of growth factors, cytokines, and proteases, which contribute to age-related tissue dysfunction. ${ }^{79,80}$

One function of the senescence response is to limit the development of fibrosis during wound healing. In the carbon tetrachloride liver fibrosis model, myofibroblasts senesce during spontaneous resolution, and produce a gene expression profile consistent with cell cycle exit, down-regulated genes encoding ECM components, and up-regulated ECM-degrading enzymes, including MMPs. ${ }^{81}$ Senescent myofibroblasts also up-regulated genes predicted to enhance immune surveillance, where they were eventually cleared by natural killer cells, thus removing the myofibroblasts and accelerating the resolution of fibrosis. When the injury was performed on mice deficient in the p53/p21 and p16 pathways, representing mice deficient in a senescence response, healing was accompanied by a marked increase in fibrosis. ${ }^{81}$ Similarly, in a mouse model of skin wounding, recruited myofibroblasts are driven into senescence at later stages of wound healing, whereupon they stopped proliferating and up-regulated expression of MMPs while also down-regulating expression of collagen and TGF$\beta{ }^{82}$ This myofibroblast senescence is triggered by the matricellular protein $\mathrm{CCN} 1$, which directly binds to integrin $\alpha_{6} \beta_{1}$ activating RAC1 to trigger accumulation of reactive oxygen species and damage response pathways inducing senescence. ${ }^{83}$ In mice expressing a mutant $\mathrm{CCN} 1$ protein that is defective in integrin binding and hence in inducing senescence, the wounds were deficient in senescent cells and mice healed with significantly more fibrosis. ${ }^{82}$

The role of senescence pathways in lung myofibroblasts is less understood. A transient senescence response was observed in fibroblasts from young mice with resolving bleomycin-induced fibrosis supporting a role for senescence in spontaneous lung fibrosis resolution. ${ }^{51}$ However, there are accumulating data supporting the fact that prolonged activation of senescent pathways contributes to persistent pulmonary fibrosis. Pulmonary fibrosis is classically, but not exclusively, a disease of aging. The incidence of IPF increases more than fivefold when comparing adults 45 to 54 years of age with those $>75$ years of age. ${ }^{84}$ Recent reviews in aging biology have identified specific biological processes that are altered in aging, and several have been associated with human pulmonary fibrosis disorders, including genomic instability, telomere erosion, epigenetic changes, proteostasis, and cellular senescence. ${ }^{85}$ Several investigators demonstrate that aged fibroblasts are profibrotic. ${ }^{53,86-89}$ Consistent findings from these studies indicate differences in the fibroblast response to injury as a primary mechanism for the greater fibrosis susceptibility among aged lungs. Compared with young mice, fibroblasts isolated from aged mice show reduced Thy- 1 expression, increased TGF- $\beta$ receptor levels, increased expression of matrix proteins when incubated with TGF- $\beta$, and a higher resistance to apoptosis. ${ }^{86,88,90}$ Senescent lung fibroblasts have been reported to resist apoptosis through the epigenetic mechanism of histone modification, resulting in up-regulation of the antiapoptotic gene, $\mathrm{Bcl}$-2, and low expression of the proapoptotic gene, $\mathrm{Bax}^{91}$

Although the aged lung is more susceptible to the onset of fibrosis, few studies in the lung or other organs specifically address the capacity for resolution of established fibrosis in aged models. Hecker et al ${ }^{51}$ demonstrated that bleomycin-induced fibrosis resolution was impaired in aged mice. In contrast to younger mice where the senescence response was transient, persistent fibrosis in the 
aged mice was associated with a prolonged senescent and apoptosis-resistant phenotype of myofibroblasts. These cellular phenotypes were mediated by an imbalance between elevated expression of the reactive oxygen species-generating enzyme Nox4 and an impaired induction of the counterregulatory response from the antioxidant Nfr2. Genetic and pharmacological targeting of Nox4 in aged mice after fibrosis enhanced the capacity for fibrosis resolution, supporting the concept that restoration of Nox4-Nrf2 reduction-oxidation balance in myofibroblasts may be a therapeutic strategy to resolve persistent fibrosis or even reverse its progression. ${ }^{51}$

In summary, although transient senescence may play an important role in myofibroblast elimination in normal wound healing, prolonged senescence of myofibroblasts in the lung induces resistance to apoptosis and may be a primary mechanism of persistent fibrosis. Supporting this hypothesis, Baker et al, ${ }^{80}$ using transgenic approaches in mice allowing for the inducible elimination of cells carrying the p16 senescence biomarker, demonstrated that life-long removal of senescent cells delays the onset of age-related phenotypes. Furthermore, late-life clearance attenuated the progression of already established agerelated disorders, including sarcopenia, cataracts, and loss of adipose tissue.$^{80}$ Collectively, these studies support that senescent cells contribute to age-related phenotypes and elimination of senescent myofibroblasts may be an effective strategy to prevent or delay age-related pathologies, such as pulmonary fibrosis.

\section{Role of Inflammatory Cells in Lung Fibrosis Resolution}

Elements of the innate and adaptive immune system have been shown to be intricately involved in lung fibrosis resolution by clearing ECM fragments and removing apoptotic cells. ${ }^{24,92}$ The indispensable role of the immune system in resolving fibrosis is highlighted by studies from Wallach-Dayan et al, ${ }^{93}$ who demonstrated myofibroblasts from mice receiving bleomycin-induced lung fibrosis resist lymphocytic Fas-induced apoptosis and survive longer when grafted into allogeneic mice. These findings support the importance of specific immune surveillance of lung myofibroblasts in the resolution of fibrosis.

The macrophage is the prototypical innate immune cell involved in chronic inflammation and fibrosis. ${ }^{94}$ Macrophages are almost always found in close proximity with collagen-producing myofibroblasts, and are believed to contribute and sustain a fibroproliferative lung microenvironment through their expression of profibrotic genes. ${ }^{92}$ The presence of these alternatively activated macrophages has been linked to acute exacerbation of IPF patients consistent with the idea that macrophages can modulate the stability or progression of IPF. ${ }^{95}$ When macrophages from the lungs of healthy controls or IPF patients were cultured and stimulated with collagen monomers, the IPFderived macrophages increased expression of profibrotic markers and cytokines, consistent with a classification of the alternative activated state. ${ }^{96}$

Although macrophages can clearly promote fibrogenesis, depletion of macrophages during the recovery phase of both toxic liver injury and the lung bleomycin fibrosis models delayed the resolution of fibrosis. ${ }^{97,98}$ These findings support that functionally distinct subpopulations of macrophages also play critical roles in recovery. Macrophages may enhance fibrosis resolution through several mechanisms: macrophages are the key sources of extracellular proteases facilitating ECM degradation; macrophages are primary cells involved in phagocytosis of cellular debris, collagen, and apoptotic cells; macrophages also recruit or activate other collagenase-producing cells, including $\mathrm{T}$ regulatory cells, which have been implicated in the suppression of fibrosis. ${ }^{92}$ The surface markers that differentiate fibrolytic macrophages and the specific precursor from which they develop have yet to be identified. However, the concept that subpopulations of macrophages can be manipulated to enhance lung fibrosis resolution was demonstrated by Redente et al, ${ }^{99}$ where pulmonary delivery of tumor necrosis factor- $\alpha$ to mice with established bleomycininduced fibrosis accelerated fibrosis resolution by directly down-regulating and reducing the number of alternatively activated macrophages.

Thus, although myofibroblasts may be master mediators of fibrosis through their synthesis of ECM components, macrophages are considered to play equally important roles by serving as the master regulators of both myofibroblast function and ECM degradation. ${ }^{92}$ Global depletion of macrophages is not a clinically feasible option to treat established and progressive disease because they are not a single rigid phenotype but pleomorphic populations. Accordingly, a key goal of future research will focus on identifying the specific macrophage subpopulations that facilitate resolution, whether these macrophage subpopulations represent a new class of recruited macrophages from the bone marrow, or if the same population of macrophages can adjust its phenotype. Identifying the signals that regulate macrophage phenotypic conversion, differentiation, or recruitment may provide methods to influence the beneficial aspects of inflammation to impede progression or reverse ongoing disease. $^{94}$

\section{Conclusions and Future Directions}

Although resolution of fibrotic remodeling occurs in normal wound healing, it remains unclear whether pulmonary fibrosis in clinical settings is reversible. Animal studies support the hypothesis that the lung has the capacity to effectively resolve a significant fibrotic burden and allow near complete predisease physiological 
recovery after removal of the fibrogenic insult. This resolution occurs through a dynamic process intricately integrated with the immune system that involves degradation and removal of the ECM and elimination of activated myofibroblasts. Several key clinical questions remain regarding lung fibrosis resolution. First, in progressive fibrotic disorders, such as IPF, how much, if any, is progression secondary to dysregulation of the resolution pathways? The higher incidence of fibrosis in the aged population and recent studies reporting impaired lung fibrosis resolution in aged rodents have high potential to determine whether resolution pathways are altered and lead to ongoing disease. Second, can innate pathways be altered to accelerate resolution in progressive fibrosis to alter the balance of deposition versus degradation? Eradication of the inciting stimulus is the most efficacious means to promote resolution, but in many progressive disorders this is often not an option. Elimination of active myofibroblasts is likely the key component to successful resolution. Recent preclinical investigations support the concept that targeting intrinsic lung myofibroblast dedifferentiation, apoptosis, or senescence pathways effectively promotes resolution and may prove to be practical approaches for treatment of lung fibrosis. ${ }^{41,50,55,70,71}$

There are clearly significant gaps in understanding lung fibrosis resolution likely reflecting the biological complexity and limitations in the animal models and basic scientific methods previously available to investigators. However, accelerated improvements in biotechnology and bioinformatics are revolutionizing biomedical research, and it is likely these new techniques and discoveries will continue to improve the understanding of the mechanisms of lung fibrosis resolution. Continued efforts focused on defining these mechanisms and determining their relevance in human disease is a critical barrier that must be crossed to lead to novel and effective restorative therapies in the treatment not only of pulmonary fibrosis, but also a wide-ranging spectrum of chronic disorders.

\section{Acknowledgment}

We thank Dr. Jeff Horowitz for his helpful assistance and advice in the preparation of this review.

\section{References}

1. King TE Jr, Bradford WZ, Castro-Bernardini S, Fagan EA, Glaspole I, Glassberg MK, Gorina E, Hopkins PM, Kardatzke D, Lancaster L, Lederer DJ, Nathan SD, Pereira CA, Sahn SA, Sussman R, Swigris JJ, Noble PW, Group AS: A phase 3 trial of pirfenidone in patients with idiopathic pulmonary fibrosis. N Engl J Med 2014, 370:2083-2092

2. Richeldi L, du Bois RM, Raghu G, Azuma A, Brown KK, Costabel U, Cottin V, Flaherty KR, Hansell DM, Inoue Y, Kim DS, Kolb M, Nicholson AG, Noble PW, Selman M, Taniguchi H, Brun M, Le Maulf F, Girard M, Stowasser S, Schlenker-Herceg R,
Disse B, Collard HR: Efficacy and safety of nintedanib in idiopathic pulmonary fibrosis. N Engl J Med 2014, 370:2071-2082

3. Rockey DC, Bell PD, Hill JA: Fibrosis: a common pathway to organ injury and failure. N Engl J Med 2015, 372:1138-1149

4. Duffield JS: Cellular and molecular mechanisms in kidney fibrosis. J Clin Invest 2014, 124:2299-2306

5. Liu X, Xu J, Brenner DA, Kisseleva T: Reversibility of liver fibrosis and inactivation of fibrogenic myofibroblasts. Curr Pathobiol Rep 2013, 1:209-214

6. Schuppan D, Kim YO: Evolving therapies for liver fibrosis. J Clin Invest 2013, 123:1887-1901

7. Brenner DA: Reversibility of liver fibrosis. Gastroenterol Hepatol 2013, 9:737-739

8. Moore BB, Hogaboam CM: Murine models of pulmonary fibrosis. Am J Physiol Lung Cell Mol Physiol 2008, 294:L152-L160

9. B Moore B, Lawson WE, Oury TD, Sisson TH, Raghavendran K, Hogaboam CM: Animal models of fibrotic lung disease. Am J Respir Cell Mol Biol 2013, 49:167-179

10. Sontake V, Shanmukhappa SK, DiPasquale BA, Reddy GB, Medvedovic M, Hardie WD, White ES, Madala SK: Fibrocytes regulate wilms tumor 1-positive cell accumulation in severe fibrotic lung disease. J Immunol 2015, 195:3978-3991

11. Degryse AL, Tanjore H, Xu XC, Polosukhin VV, Jones BR, McMahon FB, Gleaves LA, Blackwell TS, Lawson WE: Repetitive intratracheal bleomycin models several features of idiopathic pulmonary fibrosis. Am J Physiol Lung Cell Mol Physiol 2010, 299: L442-L452

12. Hardie WD, Korfhagen TR, Sartor MA, Prestridge A, Medvedovic M, Le Cras TD, Ikegami M, Wesselkamper SC, Davidson C, Dietsch M, Nichols W, Whitsett JA, Leikauf GD: Genomic profile of matrix and vasculature remodeling in TGF-alpha induced pulmonary fibrosis. Am J Respir Cell Mol Biol 2007, 37: 309-321

13. Keshari RS, Silasi-Mansat R, Zhu H, Popescu NI, Peer G, Chaaban H, Lambris JD, Polf H, Lupu C, Kinasewitz G, Lupu F: Acute lung injury and fibrosis in a baboon model of Escherichia coli sepsis. Am J Respir Cell Mol Biol 2014, 50:439-450

14. Marshall R, Bellingan G, Laurent G: The acute respiratory distress syndrome: fibrosis in the fast lane. Thorax 1998, 53:815-817

15. Burnham EL, Janssen WJ, Riches DW, Moss M, Downey GP: The fibroproliferative response in acute respiratory distress syndrome: mechanisms and clinical significance. Eur Respir J 2014, 43: 276-285

16. Burnham EL, Hyzy RC, Paine R 3rd, Coley C 2nd, Kelly AM, Quint LE, Lynch D, Janssen WJ, Moss M, Standiford TJ: Chest CT features are associated with poorer quality of life in acute lung injury survivors. Crit Care Med 2013, 41:445-456

17. Harris WT, Kelly DR, Zhou Y, Wang D, MacEwen M, Hagood JS Clancy JP, Ambalavanan N, Sorscher EJ: Myofibroblast differentiation and enhanced TGF-B signaling in cystic fibrosis lung disease. PLoS One 2013, 8:e70196

18. Booth AJ, Hadley R, Cornett AM, Dreffs AA, Matthes SA, Tsui JL, Weiss K, Horowitz JC, Fiore VF, Barker TH, Moore BB, Martinez FJ, Niklason LE, White ES: Acellular normal and fibrotic human lung matrices as a culture system for in vitro investigation. Am J Respir Crit Care Med 2012, 186:866-876

19. Amenta PS, Gil J, Martinez-Hernandez A: Connective tissue of rat lung, II: ultrastructural localization of collagen types III, IV, and VI. J Histochem Cytochem 1988, 36:1167-1173

20. Sobin SS, Fung YC, Tremer HM: Collagen and elastin fibers in human pulmonary alveolar walls. J Appl Physiol (1985) 1988, 64: $1659-1675$

21. Bateman ED, Turner-Warwick M, Adelmann-Grill BC: Immunohistochemical study of collagen types in human foetal lung and fibrotic lung disease. Thorax 1981, 36:645-653

22. Snider GL: Collagen concentration and rates of synthesis in idiopathic pulmonary fibrosis. Am Rev Respir Dis 1981, 124:341-342 
23. Giannandrea M, Parks WC: Diverse functions of matrix metalloproteinases during fibrosis. Dis Model Mech 2014, 7:193-203

24. McKleroy W, Lee TH, Atabai K: Always cleave up your mess: targeting collagen degradation to treat tissue fibrosis. Am J Physiol Lung Cell Mol Physiol 2013, 304:L709-L721

25. Everts V, van der Zee E, Creemers L, Beertsen W: Phagocytosis and intracellular digestion of collagen, its role in turnover and remodelling. Histochem J 1996, 28:229-245

26. Iredale JP, Thompson A, Henderson NC: Extracellular matrix degradation in liver fibrosis: biochemistry and regulation. Biochim Biophys Acta 2013, 1832:876-883

27. Gill SE, Huizar I, Bench EM, Sussman SW, Wang Y, Khokha R, Parks WC: Tissue inhibitor of metalloproteinases 3 regulates resolution of inflammation following acute lung injury. Am J Pathol 2010, 176:64-73

28. Kim KH, Burkhart K, Chen P, Frevert CW, Randolph-Habecker J, Hackman RC, Soloway PD, Madtes DK: Tissue inhibitor of metalloproteinase-1 deficiency amplifies acute lung injury in bleomycin-exposed mice. Am J Respir Cell Mol Biol 2005, 33: $271-279$

29. Dancer RC, Wood AM, Thickett DR: Metalloproteinases in idiopathic pulmonary fibrosis. Eur Respir J 2011, 38:1461-1467

30. Arpino V, Brock M, Gill SE: The role of TIMPs in regulation of extracellular matrix proteolysis. Matrix Biol 2015, 44-46: $247-254$

31. Yamauchi M, Sricholpech M: Lysine post-translational modifications of collagen. Essays Biochem 2012, 52:113-133

32. Rosin NL, Sopel MJ, Falkenham A, Lee TD, Légaré JF: Disruption of collagen homeostasis can reverse established age-related myocardial fibrosis. Am J Pathol 2015, 185:631-642

33. Barry-Hamilton V, Spangler R, Marshall D, McCauley S, Rodriguez HM, Oyasu M, Mikels A, Vaysberg M, Ghermazien H, Wai C, Garcia CA, Velayo AC, Jorgensen B, Biermann D, Tsai D, Green J, Zaffryar-Eilot S, Holzer A, Ogg S, Thai D, Neufeld G, Van Vlasselaer P, Smith V: Allosteric inhibition of lysyl oxidase-like-2 impedes the development of a pathologic microenvironment. Nat Med 2010, 16:1009-1017

34. Bundesmann MM, Wagner TE, Chow YH, Altemeier WA, Steinbach T, Schnapp LM: Role of urokinase plasminogen activator receptor-associated protein in mouse lung. Am J Respir Cell Mol Biol 2012, 46:233-239

35. Lee W, Sodek J, McCulloch CA: Role of integrins in regulation of collagen phagocytosis by human fibroblasts. J Cell Physiol 1996, 168:695-704

36. East L, McCarthy A, Wienke D, Sturge J, Ashworth A, Isacke CM: A targeted deletion in the endocytic receptor gene Endo180 results in a defect in collagen uptake. EMBO Rep 2003, 4:710-716

37. Atabai K, Jame S, Azhar N, Kuo A, Lam M, McKleroy W, Dehart G, Rahman S, Xia DD, Melton AC, Wolters P, Emson CL, Turner SM, Werb Z, Sheppard D: Mfge8 diminishes the severity of tissue fibrosis in mice by binding and targeting collagen for uptake by macrophages. J Clin Invest 2009, 119:3713-3722

38. Atabai K, Fernandez R, Huang X, Ueki I, Kline A, Li Y, Sadatmansoori S, Smith-Steinhart C, Zhu W, Pytela R, Werb Z, Sheppard D: Mfge8 is critical for mammary gland remodeling during involution. Mol Biol Cell 2005, 16:5528-5537

39. Yang X, Chen B, Liu T, Chen X: Reversal of myofibroblast differentiation: a review. Eur J Pharmacol 2014, 734:83-90

40. Hecker L, Jagirdar R, Jin T, Thannickal VJ: Reversible differentiation of myofibroblasts by MyoD. Exp Cell Res 2011, 317: 1914-1921

41. Zhou Y, Huang X, Hecker L, Kurundkar D, Kurundkar A, Liu H, Jin TH, Desai L, Bernard K, Thannickal VJ: Inhibition of mechanosensitive signaling in myofibroblasts ameliorates experimental pulmonary fibrosis. J Clin Invest 2013, 123: 1096-1108
42. Zhou Y, Hagood JS, Lu B, Merryman WD, Murphy-Ullrich JE: Thy1-integrin alphav beta5 interactions inhibit lung fibroblast contraction-induced latent transforming growth factor-beta1 activation and myofibroblast differentiation. J Biol Chem 2010, 285: 22382-22393

43. Puri S, Folias AE, Hebrok M: Plasticity and dedifferentiation within the pancreas: development, homeostasis, and disease. Cell Stem Cell 2015, 16:18-31

44. Eguizabal C, Montserrat N, Veiga A, Izpisua Belmonte JC: Dedifferentiation, transdifferentiation, and reprogramming: future directions in regenerative medicine. Semin Reprod Med 2013, 31: $82-94$

45. Friedmann-Morvinski D, Verma IM: Dedifferentiation and reprogramming: origins of cancer stem cells. EMBO Rep 2014, 15: 244-253

46. Kisseleva T, Cong M, Paik Y, Scholten D, Jiang C, Benner C, Iwaisako K, Moore-Morris T, Scott B, Tsukamoto H, Evans SM, Dillmann W, Glass CK, Brenner DA: Myofibroblasts revert to an inactive phenotype during regression of liver fibrosis. Proc Natl Acad Sci U S A 2012, 109:9448-9453

47. Troeger JS, Mederacke I, Gwak GY, Dapito DH, Mu X, Hsu CC, Pradere JP, Friedman RA, Schwabe RF: Deactivation of hepatic stellate cells during liver fibrosis resolution in mice. Gastroenterology 2012, 143:1073-1083.e22

48. Golan-Gerstl R, Wallach-Dayan SB, Zisman P, Cardoso WV, Goldstein RH, Breuer R: Cellular FLICE-like inhibitory protein deviates myofibroblast fas-induced apoptosis toward proliferation during lung fibrosis. Am J Respir Cell Mol Biol 2012, 47: $271-279$

49. Ramos C, Montano M, Becerril C, Cisneros-Lira J, Barrera L, Ruiz V, Pardo A, Selman M: Acidic fibroblast growth factor decreases alpha-smooth muscle actin expression and induces apoptosis in human normal lung fibroblasts. Am J Physiol Lung Cell Mol Physiol 2006, 291:L871-L879

50. Reddy AT, Lakshmi SP, Zhang Y, Reddy RC: Nitrated fatty acids reverse pulmonary fibrosis by dedifferentiating myofibroblasts and promoting collagen uptake by alveolar macrophages. FASEB J 2014, 28:5299-5310

51. Hecker L, Logsdon NJ, Kurundkar D, Kurundkar A, Bernard K, Hock T, Meldrum E, Sanders YY, Thannickal VJ: Reversal of persistent fibrosis in aging by targeting Nox4-Nrf2 redox imbalance. Sci Transl Med 2014, 6:231ra47

52. Artaud-Macari E, Goven D, Brayer S, Hamimi A, Besnard V, Marchal-Somme J, Ali ZE, Crestani B, Kerdine-Romer S, Boutten A, Bonay M: Nuclear factor erythroid 2-related factor 2 nuclear translocation induces myofibroblastic dedifferentiation in idiopathic pulmonary fibrosis. Antioxid Redox Signal 2013, 18: 66-79

53. Huang WT, Akhter H, Jiang C, MacEwen M, Ding Q, Antony V, Thannickal VJ, Liu RM: Plasminogen activator inhibitor 1, fibroblast apoptosis resistance, and aging-related susceptibility to lung fibrosis. Exp Gerontol 2015, 61:62-75

54. Garrison G, Huang SK, Okunishi K, Scott JP, Kumar Penke LR, Scruggs AM, Peters-Golden M: Reversal of myofibroblast differentiation by prostaglandin E(2). Am J Respir Cell Mol Biol 2013, 48: $550-558$

55. Sisson TH, Ajayi IO, Subbotina N, Dodi AE, Rodansky ES, Chibucos LN, Kim KK, Keshamouni VG, White ES, Zhou Y, Higgins PD, Larsen SD, Neubig RR, Horowitz JC: Inhibition of myocardin-related transcription factor/serum response factor signaling decreases lung fibrosis and promotes mesenchymal cell apoptosis. Am J Pathol 2015, 185:969-986

56. Horowitz JC, Ajayi IO, Kulasekaran P, Rogers DS, White JB, Townsend SK, White ES, Nho RS, Higgins PD, Huang SK, Sisson TH: Survivin expression induced by endothelin-1 promotes myofibroblast resistance to apoptosis. Int J Biochem Cell Biol 2012, $44: 158-169$ 
57. Kulasekaran P, Scavone CA, Rogers DS, Arenberg DA, Thannickal VJ, Horowitz JC: Endothelin-1 and transforming growth factor-beta1 independently induce fibroblast resistance to apoptosis via AKT activation. Am J Respir Cell Mol Biol 2009, 41: 484-493

58. Sanders YY, Tollefsbol TO, Varisco BM, Hagood JS: Epigenetic regulation of thy-1 by histone deacetylase inhibitor in rat lung fibroblasts. Am J Respir Cell Mol Biol 2011, 45:16-23

59. Ajayi IO, Sisson TH, Higgins PD, Booth AJ, Sagana RL, Huang SK, White ES, King JE, Moore BB, Horowitz JC: X-linked inhibitor of apoptosis regulates lung fibroblast resistance to Fas-mediated apoptosis. Am J Respir Cell Mol Biol 2013, 49:86-95

60. Weintraub H, Davis R, Tapscott S, Thayer M, Krause M, Benezra R, Blackwell TK, Turner D, Rupp R, Hollenberg S, Zhuang Y, Lassar A: The myoD gene family: nodal point during specification of the muscle cell lineage. Science 1991, 251:761-766

61. Maltseva O, Folger P, Zekaria D, Petridou S, Masur SK: Fibroblast growth factor reversal of the corneal myofibroblast phenotype. Invest Ophthalmol Vis Sci 2001, 42:2490-2495

62. Sanders YY, Pardo A, Selman M, Nuovo GJ, Tollefsbol TO, Siegal GP, Hagood JS: Thy-1 promoter hypermethylation: a novel epigenetic pathogenic mechanism in pulmonary fibrosis. Am J Respir Cell Mol Biol 2008, 39:610-618

63. Wettlaufer SH, Scott JP, McEachin RC, Peters-Golden M, Huang SK: Reversal of the transcriptome by prostaglandin $\mathrm{E}_{2}$ during myofibroblast dedifferentiation. Am J Respir Cell Mol Biol 2016, 54:114-127

64. Dackor RT, Cheng J, Voltz JW, Card JW, Ferguson CD, Garrett RC, Bradbury JA, DeGraff LM, Lih FB, Tomer KB, Flake GP, Travlos GS, Ramsey RW Jr, Edin ML, Morgan DL, Zeldin DC: Prostaglandin E(2) protects murine lungs from bleomycin-induced pulmonary fibrosis and lung dysfunction. Am J Physiol Lung Cell Mol Physiol 2011, 301:L645-L655

65. Zhao C, Chen W, Yang L, Chen L, Stimpson SA, Diehl AM: PPARgamma agonists prevent TGFbeta1/Smad3-signaling in human hepatic stellate cells. Biochem Biophys Res Commun 2006, 350: 385-391

66. Milam JE, Keshamouni VG, Phan SH, Hu B, Gangireddy SR, Hogaboam CM, Standiford TJ, Thannickal VJ, Reddy RC: PPARgamma agonists inhibit profibrotic phenotypes in human lung fibroblasts and bleomycin-induced pulmonary fibrosis. Am J Physiol Lung Cell Mol Physiol 2008, 294:L891-L901

67. Hotchkiss RS, Strasser A, McDunn JE, Swanson PE: Cell death. N Engl J Med 2009, 361:1570-1583

68. Thannickal VJ, Horowitz JC: Evolving concepts of apoptosis in idiopathic pulmonary fibrosis. Proc Am Thorac Soc 2006, 3:350-356

69. Desmouliere A, Redard M, Darby I, Gabbiani G: Apoptosis mediates the decrease in cellularity during the transition between granulation tissue and scar. Am J Pathol 1995, 146:56-66

70. Ashley SL, Sisson TH, Wheaton AK, Kim KK, Wilke CA, Ajayi IO, Subbotina N, Wang S, Duckett CS, Moore BB, Horowitz JC: Targeting inhibitor of apoptosis proteins protects from bleomycininduced lung fibrosis. Am J Respir Cell Mol Biol 2016, 54:482-492

71. Sanders YY, Hagood JS, Liu H, Zhang W, Ambalavanan N, Thannickal VJ: Histone deacetylase inhibition promotes fibroblast apoptosis and ameliorates pulmonary fibrosis in mice. Eur Respir J 2014, 43:1448-1458

72. Horowitz JC, Thannickal VJ: Fibroblast biology in idiopathic pulmonary fibrosis. Edited by Annie P, Selman M. Contemporary Approaches to Idiopathic Pulmonary Fibrosis. London: Future Medicine Ltd, 2015, pp 99-118

73. Nho RS, Hergert P, Kahm J, Jessurun J, Henke C: Pathological alteration of FoxO3a activity promotes idiopathic pulmonary fibrosis fibroblast proliferation on type i collagen matrix. Am J Pathol 2011, 179:2420-2430

74. White ES, Thannickal VJ, Carskadon SL, Dickie EG, Livant DL, Markwart S, Toews GB, Arenberg DA: Integrin alpha4betal regulates migration across basement membranes by lung fibroblasts: a role for phosphatase and tensin homologue deleted on chromosome 10. Am J Respir Crit Care Med 2003, 168:436-442

75. Liu F, Mih JD, Shea BS, Kho AT, Sharif AS, Tager AM, Tschumperlin DJ: Feedback amplification of fibrosis through matrix stiffening and COX-2 suppression. J Cell Biol 2010, 190: 693-706

76. Huang SK, Scruggs AM, Donaghy J, Horowitz JC, Zaslona Z, Przybranowski S, White ES, Peters-Golden M: Histone modifications are responsible for decreased Fas expression and apoptosis resistance in fibrotic lung fibroblasts. Cell Death Dis 2013, 4:e621

77. Campisi J, d'Adda di Fagagna F: Cellular senescence: when bad things happen to good cells. Nat Rev Mol Cell Biol 2007, 8:729-740

78. Rayess H, Wang MB, Srivatsan ES: Cellular senescence and tumor suppressor gene p16. Int J Cancer 2012, 130:1715-1725

79. Itahana K, Campisi J, Dimri GP: Mechanisms of cellular senescence in human and mouse cells. Biogerontology 2004, 5:1-10

80. Baker DJ, Wijshake T, Tchkonia T, LeBrasseur NK, Childs BG, van de Sluis B, Kirkland JL, van Deursen JM: Clearance of p16Ink4apositive senescent cells delays ageing-associated disorders. Nature 2011, 479:232-236

81. Krizhanovsky V, Yon M, Dickins RA, Hearn S, Simon J, Miething C, Yee H, Zender L, Lowe SW: Senescence of activated stellate cells limits liver fibrosis. Cell 2008, 134:657-667

82. Jun JI, Lau LF: Cellular senescence controls fibrosis in wound healing. Aging 2010, 2:627-631

83. Chen CC, Lau LF: Functions and mechanisms of action of CCN matricellular proteins. Int J Biochem Cell Biol 2009, 41:771-783

84. Thannickal VJ, Murthy M, Balch WE, Chandel NS, Meiners S, Eickelberg O, Selman M, Pardo A, White ES, Levy BD, Busse PJ, Tuder RM, Antony VB, Sznajder JI, Budinger GR: Blue journal conference: aging and susceptibility to lung disease. Am J Respir Crit Care Med 2015, 191:261-269

85. Lopez-Otin C, Blasco MA, Partridge L, Serrano M, Kroemer G: The hallmarks of aging. Cell 2013, 153:1194-1217

86. Naik PN, Horowitz JC, Moore TA, Wilke CA, Toews GB, Moore BB: Pulmonary fibrosis induced by gamma-herpesvirus in aged mice is associated with increased fibroblast responsiveness to transforming growth factor-beta. J Gerontol A Biol Sci Med Sci 2012, $67: 714-725$

87. Redente EF, Jacobsen KM, Solomon JJ, Lara AR, Faubel S, Keith RC, Henson PM, Downey GP, Riches DW: Age and sex dimorphisms contribute to the severity of bleomycin-induced lung injury and fibrosis. Am J Physiol Lung Cell Mol Physiol 2011, 301: L510-L518

88. Sueblinvong V, Neujahr DC, Mills ST, Roser-Page S, Ritzenthaler JD, Guidot D, Rojas M, Roman J: Predisposition for disrepair in the aged lung. Am J Med Sci 2012, 344:41-51

89. Torres-Gonzalez E, Bueno M, Tanaka A, Krug LT, Cheng DS, Polosukhin VV, Sorescu D, Lawson WE, Blackwell TS, Rojas M, Mora AL: Role of endoplasmic reticulum stress in age-related susceptibility to lung fibrosis. Am J Respir Cell Mol Biol 2012, 46: $748-756$

90. Sueblinvong V, Neveu WA, Neujahr DC, Mills ST, Rojas M, Roman J, Guidot DM: Aging promotes pro-fibrotic matrix production and increases fibrocyte recruitment during acute lung injury. Adv Biosci Biotechnol 2014, 5:19-30

91. Sanders YY, Liu H, Zhang X, Hecker L, Bernard K, Desai L, Liu G, Thannickal VJ: Histone modifications in senescenceassociated resistance to apoptosis by oxidative stress. Redox Biol 2013, 1:8-16

92. Wynn TA, Barron L: Macrophages: master regulators of inflammation and fibrosis. Semin Liver Dis 2010, 30:245-257

93. Wallach-Dayan SB, Golan-Gerstl R, Breuer R: Evasion of myofibroblasts from immune surveillance: a mechanism for tissue fibrosis. Proc Natl Acad Sci U S A 2007, 104:20460-20465

94. Wynn TA, Ramalingam TR: Mechanisms of fibrosis: therapeutic translation for fibrotic disease. Nat Med 2012, 18:1028-1040 
95. Schupp JC, Binder H, Jager B, Cillis G, Zissel G, MullerQuernheim J, Prasse A: Macrophage activation in acute exacerbation of idiopathic pulmonary fibrosis. PLoS One 2015, 10:e0116775

96. Stahl M, Schupp J, Jager B, Schmid M, Zissel G, MullerQuernheim J, Prasse A: Lung collagens perpetuate pulmonary fibrosis via CD204 and M2 macrophage activation. PLoS One 2013, 8: e81382

97. Gibbons MA, MacKinnon AC, Ramachandran P, Dhaliwal K, Duffin R, Phythian-Adams AT, van Rooijen N, Haslett C, Howie SE, Simpson AJ, Hirani N, Gauldie J, Iredale JP, Sethi T, Forbes SJ: Ly6Chi monocytes direct alternatively activated profibrotic macrophage regulation of lung fibrosis. Am J Respir Crit Care Med 2011, 184:569-581

98. Duffield JS, Forbes SJ, Constandinou CM, Clay S, Partolina M, Vuthoori S, Wu S, Lang R, Iredale JP: Selective depletion of macrophages reveals distinct, opposing roles during liver injury and repair. J Clin Invest 2005, 115:56-65

99. Redente EF, Keith RC, Janssen W, Henson PM, Ortiz LA, Downey GP, Bratton DL, Riches DW: Tumor necrosis factor-alpha accelerates the resolution of established pulmonary fibrosis in mice by targeting profibrotic lung macrophages. Am J Respir Cell Mol Biol 2014, 50:825-837 